\title{
Delayed subclavian vein stent perforation causing adjacent arterial pseudoaneurysm formation in a patient with granulomatosis with polyangiitis
}

\author{
Alexander SM Tan ${ }^{1 *}$, Jasmine ME Chua ${ }^{1}$, Ankur Patel $^{1}$ \\ 1. Department of Vascular and Interventional Radiology, Singapore General Hospital, Singapore \\ * Correspondence: Alexander Sheng Ming Tan, Department of Vascular and Interventional Radiology, Singapore General Hospital, \\ Outram Road, Singapore 169608, Singapore \\ (入alexander.tan@mohh.com.sg)
}

Radiology Case. 2020 Apr; 14(4):8-20 :: $\quad$ DOI: 10.3941/jrcr.v14i4.3903

\begin{abstract}
Stenting is necessary when vascular patency is not adequately achieved with angioplasty alone. Common causes of pseudoaneurysms are iatrogenic and traumatic. We describe a case of a perforated left subclavian vein Gianturco stent causing a pseudoaneurysm of the left common carotid artery in a patient with granulomatosis with polyangiitis, detected 8 years after stent insertion.
\end{abstract}

\section{CASE REPORT}

\section{CASE REPORT}

A 49-year-old Indian man with long-standing history of granulomatosis with polyangiitis (GPA; previously known as Wegener's granulomatosis), presented to the emergency department with exertional dyspnea and intermittent cough. His systemic vasculitis was not optimally treated and complicated by glomerulonephritis, end stage renal failure, and recurrent episodes of pulmonary hemorrhage and pneumonia. He had multiple endovascular interventions for his hemodialysis access sites. His left arm arteriovenous fistula had failed after repeated interventions which included stenting of left subclavian vein stenosis with a $40 \times 50 \mathrm{~mm}$ Gianturco Z-stent (Cook Medical, Bloomington, Indiana, USA) 8 years ago with suboptimal result (Fig. 1). He was receiving hemodialysis via a right arm arteriovenous graft.

On examination, he was alert with findings of bilateral crepitations on lung auscultation. He was admitted with the clinical impression of pneumonia. Despite being on intravenous antibiotics, he deteriorated clinically with episodes of desaturation. He was also started on azathioprine and prednisolone for treatment of pulmonary involvement by the systemic vasculitis.

His inpatient chest X-rays (CXRs) demonstrated progressive white-out of the left hemithorax (Fig. 2). This was evaluated with a contrast-enhanced computed tomography (CT) scan of the thorax which showed multiple recurring nodular lesions (Fig. 3), some of which were cavitating 8 months ago (Fig. 4). This was deemed likely to be manifestation of the systemic vasculitis with possible superimposed fungal infection. Incidentally, a $1.3 \times 1.0 \mathrm{~cm}$ proximal left common carotid artery (CCA) pseudoaneurysm (PSA), adjacent to protruding struts of the left subclavian vein Gianturco stent was identified (Fig. 5). This was new since the previous CT 8 months before. The lateral end of the stent was mangled and deformed, likely due to mechanical compression and shearing forces in the subclavian region and the left subclavian vein appeared occluded with prominent left upper chest wall collaterals seen (Fig. 6). Given his poorly controlled systemic vasculitis, ongoing pneumonia and 
immunocompromised state, the patient was not an ideal surgical candidate. Hence, he was referred to Interventional Radiology for endovascular management of the left CCA PSA.

Written informed consent was obtained for covered stenting of the left CCA PSA. The procedure was performed under local anesthesia. Through a right common femoral artery retrograde access, selective right internal carotid, left vertebral and left common carotid angiograms were obtained to exclude any intracranial aneurysm or significant stenosis. Left CCA angiogram demonstrated the focal PSA sac at its proximal segment, pointing medially (Fig. 7a). The left subclavian vein stent struts were projected over the proximal left CCA.

A 7 x $37 \mathrm{~mm}$ BeGraft peripheral stent (Bentley Innomed $\mathrm{GmbH}$, Germany) was deployed across the neck of the PSA. The proximal end of the stent at the ostium of the left CCA was further dilated with balloon inflation to 'flare' the edge (Fig. 7c). Final angiogram confirmed successful occlusion of the PSA with no flow visualized (Fig. 7d). Finally, hemostasis was secured with a Perclose Proglide vascular closure device (Abbott Vascular, Santa Clara, California, USA).

Post stenting, the patient was started on dual antiplatelet therapy of lifelong aspirin and 3 months' duration of clopidogrel. His post procedure recovery was uneventful and he was discharged 6 days later. Subsequent CT 4 months post stenting showed continued occlusion of the left CCA PSA and patency of the stent (Fig. 8a to 8c), with interval improvement of the lung nodules (Fig. 8d to 8f).

\section{DISCUSSION}

A PSA is the contained extravasation of blood within the adjacent extra-luminal space from an arterial wall defect [1].

\section{Etiology \& Demographics:}

The most common cause for loss of arterial wall integrity is iatrogenic. It is a known complication in endovascular procedures, non-vascular percutaneous procedures such as biopsy or drainage, surgical procedures involving arterial anastomosis such as arterial bypass or repair and transplantation for example, and obstetric procedures such as uterine dilatation and curettage, and Cesarean section. Aside from iatrogenic causes, blunt and penetrating trauma, infection (mycotic) and inflammation either primarily of the arteries (vasculitis) or the adjacent viscera (e.g. pancreatitis) are possible etiologies [2].

Blood dissects through and around the damaged artery under sustained arterial pressure, forming a perfused sac that communicates with the arterial lumen. This sac is bound by the arterial media or adventitia, or the surrounding soft-tissue structures. This is distinct from a true aneurysm which is arterial dilatation formed by all three arterial wall layers (intima, media and adventitia) [2].
The incidence of PSAs varies according to etiology. For example, it ranges from $0.05 \%$ to $2 \%$ for diagnostic catheterization. This is increased to $2 \%$ to $6 \%$ in the setting of coronary or peripheral intervention, and in the population receiving antithrombotic and antiplatelet therapy [3]. There is no particular gender or age predilection.

\section{Clinical \& Imaging Findings.}

PSAs may be asymptomatic and discovered incidentally during imaging as in this case, or they can be symptomatic and manifest as a pulsatile swelling, palpable thrill or audible bruit on clinical examination. Local mass effect may cause vascular compromise and skin necrosis, neurological deficit due to nerve compression, limb edema and deep venous thrombosis due to venous compression, and thromboembolism. Rupture may result in hemodynamic instability and hypovolemic shock - the most significant cause of morbidity. PSAs can communicate with and rupture into the gastrointestinal tract, biliary tree, mediastinal, pleural, peritoneal and retroperitoneal spaces, which may present with sentinel bleeding from a drainage catheter, hematemesis or melena [2].

Although not performed in this case, ultrasonography (US) is a common first line modality in detecting a PSA in superficial locations, particularly at vascular access sites. It is readily available, portable, low cost, fast and does not expose the patient to ionizing radiation or nephrotoxic contrast. A PSA appears as a hypoechoic cystic structure close to a supplying artery or within a solid organ showing turbulent flow on color Doppler (yin-yang sign). The hallmark finding is a communicating channel between the sac and feeding artery with bidirectional waveform in systole and diastole respectively on spectral Doppler [2].

On CT/Computed Tomography Angiography (CTA), a PSA is seen as a low-attenuation rounded structure close to a supplying artery on the non-contrast phase if external to solid organs. A PSA within a solid organ is difficult to detect without intravenous (IV) contrast. High or intermediate attenuation density adjacent to the PSA suggests a hematoma due to rupture (attenuation varies depending on the age of the hematoma). On the post-contrast phases, it is seen as a contrast filled sac close to a supplying artery or within a solid organ [2]. It may not fill with contrast if thrombosed.

Magnetic Resonance Angiography (MRA) is an alternative to CTA, particularly for patients with allergy to iodinated contrast media or who are pregnant. Gadoliniumenhanced MRA offers 3D visualization of the PSA, any thrombus within, and surrounding structures with superior tissue contrast resolution. However, its use in the emergent setting is limited by cost, time required, availability outside office hours, and contraindication posed by implants [2]. MR vascular imaging techniques are complex and beyond the scope of this case report. MRA was not performed for this patient.

Catheter angiography remains the reference standard for imaging diagnosis of a PSA. Similar to CTA, it is seen as a contrast filled sac close to a supplying artery or within a solid organ [2]. It may not fill with contrast if thrombosed. 
Differential Diagnoses:

All forms of PSAs share similar core imaging features hence it is the clinical history that differentiates them.

\section{Iatrogenic}

A history of vascular procedures or non-vascular procedures that potentially transgress arteries and the presence on imaging of a catheter, graft or stent, or evidence of previous intervention/surgery such as coils or clips suggests iatrogenic etiology.

\section{Traumatic}

PSA formation is one important pattern of vascular injury that should be routinely assessed for in the setting of trauma. There is often co-existing solid organ injury and other trauma related findings such as fractures and foreign bodies on CT.

\section{Infection}

The patient may be febrile and septic with raised inflammatory markers. Bacteremia, traditionally Grampositive cocci or Salmonella, is associated with Mycotic aneurysm formation [4]. A thickened, irregular, or ill-defined sac wall with surrounding fat stranding on CT or MRI is suggestive of a mycotic PSA [2].

\section{Inflammation}

In the setting of systemic vasculitis, for example Behçet's syndrome, polyarteritis nodosa (PAN), systemic lupus erythematosus (SLE), giant cell arteritis (GCA), and Takayasu's arteritis, there are typically multiple sites and systems involved such as the mucous membranes, skin, eyes and kidneys. Chronic inflammation destroys the elastic fibers of the media resulting in pseudoaneurysm formation. PSAs caused by primary vasculitis are relatively rare, but many cases have been reported with Behçet's syndrome in particular, with the frequency of vascular involvement in Behçet's syndrome estimated to range from $2 \%$ to $46 \%$. The aorta is the most common site of PSA, followed by the pulmonary, femoral, subclavian, and popliteal arteries [5].

A history of alcohol excess or cholelithiasis and elevated serum amylase and lipase are suggestive of pancreatitis. Associated pancreatic swelling with peripancreatic fat stranding and fluid would be seen on CT or MRI.

\section{True aneurysm}

A true aneurysm is formed by all three layers of the arterial wall and hence appears as a hypoechoic cystic structure in clear continuity with the artery on US showing arterial flow on color Doppler. On CT/CTA and catheter angiography, it is seen as a contrast filled fusiform dilatation or saccular outpouching in continuity with the artery [2].

\section{Treatment \& Prognosis:}

The prognosis of a PSA is difficult to predict save for certain particular etiologies. Some undergo spontaneous thrombosis while other progress with development of complications as mentioned above, the most feared of which is rupture with potentially life-threatening hemorrhage. Visceral artery PSAs external to solid organs in particular have a very high risk of spontaneous rupture regardless of their size and warrant active intervention.
The traditional treatment for PSAs has been surgical repair. This is invasive and often associated with significantly higher morbidity and mortality. Minimally invasive image guided treatments are current alternatives to surgery, such as US guided compression, US guided percutaneous thrombin injection, and endoluminal management (stenting and embolization) [2].

Complications of vascular stents include stenosis recurrence, malposition, migration, deformation/fracture and vessel perforation $[6,7,8,9]$. There have been reported cases of Gianturco stent perforation of dialysis access grafts and the trachea respectively $[10,11]$. PSA formation following central venous catheter insertion, and in a patient with SLE following arterial line insertion have been reported [12,13,14]. To the best of our knowledge and literature review, venous stent perforation causing PSA formation has not been described before.

The Gianturco Rosch Z stent (Cook Inc, Bloomington, Indiana, USA) was first described in the treatment of superior vena cava syndrome (SVCS) in the late 1980s and 1990s $[15,16]$. It was also used to treat tracheobronchial stenoses [17]. They are large-diameter self-expanding open-cell stents made from a stainless-steel monofilament wire bent into 'zigzag' configuration to form a cylinder (Fig 9). It was previously one of the preferred stents for treatment of central vein obstructions because of its availability in large sizes (20-40 $\mathrm{mm}$ diameter), high radial strength and resilience to deformation in a location prone to external compression.

When deployed, the high radial outward force of the Gianturco stent completely apposes the stent to vessel wall if adequately sized. Its hooks/ barbs become incorporated in the vein wall. Even though the stabilizing barbs retard migration arguably the greatest and potentially fatal risk to central venous stent placement; they carry a theoretical predisposition to perforation [18]. Their role in vessel wall injury and subsequent neointima formation has been studied in animals [19]. Animal model studies of hemodialysis grafts showed more inflammatory response to the Gianturco stent than Wallstent [20], Experimental animal study by Puma et al of bronchial stenting with Gianturco revealed deep full thickness ulcerations of the bronchial wall at the stent's anchoring sites on microscopic evaluation 12 months after insertion. Their observations were that Gianturco stent is unsafe in the long term due to progression to its maximum diameter, weakening the luminal wall, which undergoes erosion until perforation [21].

We postulate that Gianturco stent perforation of the subclavian vein wall was multifactorial in this case. Aside from the inherent superior radial strength of the Gianturco stent, stent oversizing and the predisposition of the subclavian vein to movement and external compression are likely contributory. The latter factor was described by Mallios et al [6]. Vein wall perforation by stent/filter struts can be treated conservatively, however it can be potentially fatal when the struts further expand outward to traumatize vital structures such as the major arteries. In this patient, poorly controlled GPA, a form of small- and medium-size vasculitis, probably 
predisposed him to PSA formation, although large vessel aneurysm is not a classical finding in GPA. Nonetheless, aortic aneurysms have been encountered in GPA patients; Niimi et al reported successful treatment with medical therapy [22,23]. Shitrit et al described a case of GPA complicated by subclavian artery aneurysm. Their review of the literature on large-vessel and medium-vessel aneurysms in GPA found involvement of the aorta and the hepatic, renal, and left gastric arteries, presenting with abdominal pain in all but one case. In two patients, rupture led to massive hemorrhage and death [24].

\section{TEACHING POINT}

This case illustrates that knowledge of stent design, mechanical properties and size is crucial for selecting the appropriate stent for a particular vessel and lesion type. An inappropriate choice may have repercussions even many years later. In the event stent fracture and/or vessel wall perforation is detected on follow up, active search for evidence of injury to adjacent structures, particular arterial, should be routine.

\section{REFERENCES}

1. CPE Milne, Lee R, Handa AI. Iatrogenic Pseudoaneurysms. Vascular Surgery - Principles and Practice. INTECH Open Access Publisher; 2012. https://www.intechopen.com/books/vascular-surgeryprinciples-and-practice/iatrogenic-pseudoaneurysms . doi: $10.5772 / 51494$

2. Nael EA Saad, Wael EA Saad, Mark G Davies, David L Waldman, Patrick J Fultz, Deborah J Rubens. Pseudoaneurysms and the Role of Minimally Invasive Techniques in Their Management. RadioGraphics 2005 25:suppl_1, S173-S189. PMID: 16227490

3. Webber GW, Jang J, Gustavson S, Olin JW. Contemporary Management of Postcatheterization Pseudoaneurysms. Circulation, 2007;115(20), 2666-2674. PMID: 17515479

4. Chung-Ching Lee, Yee-Yung Ng, Yi-Hong Chou, Chui-Mei Tiu, Zing Wang, Hui-Ming Yang, Tzen-Wen Chen, WuChang Yang, Mycotic Aneurysm of the Abdominal Aorta in a Patient Undergoing Hemodialysis: An Unusual Complication of Staphylococcus aureus Bacteremia, Clinical Infectious Diseases, Volume 30, Issue 5, May 2000, Pages 823-824. PMID: 10816154

5. Ko GY, Byun JY, Choi BG, et al. The vascular manifestations of Behçet disease: angiographic and CT findings. $\mathrm{Br} \mathrm{J}$ Radiol $2000 \mathrm{Dec}$;3(876):1270-4. PMID: 11205670

6. Mallios A, Taubman K, Claiborne P, Blebea J. Subclavian Vein Stent Fracture and Venous Motion. Ann Vasc Surg. 2015 Oct;29(7):1451.e1-4. PMID: 26122410
7. Kang W, Kim IS, Kim JU, Cheon JH, Kim SK, Ko SH, Kim SH, Lee SW, Cho SH. Surgical removal of endovascular stent after migration to the right ventricle following right subclavian vein deployment for treatment of central venous stenosis. J Cardiovasc Ultrasound. 2011 Dec;19(4):203-6. PMID: 22259665

8. Bagul NB, Moth P, Menon NJ, Myint F, Hamilton G. Migration of superior vena cava stent. J Cardiothorac Surg. 2008 Mar 10;3:12. PMID: 18331639

9. Martin M, Baumgartner I, Kolb M, Triller J, Dinkel HP. Fatal pericardial tamponade after Wallstent implantation for malignant superior vena cava syndrome. J Endovasc Ther. 2002;9(5):680-684. PMID: 12431154

10. Beathard GA. Gianturco self-expanding stent in the treatment of stenosis in dialysis access grafts. Kidney Int 1993;43:872-7. PMID: 8479123

11. Sanjay Asopa, Narain Moorjani, Rasheed A. Saad, Jonathan T. Turner KMA. Rare and Fatal Complication of Gianturco Tracheobronchial Stent. Ann Thorac Surg 2007;84:1758-60. PMID: 17954110

12. M K, Kang E, Kim H, et al. Delayed Presentation of Catheter-related Subclavian Artery Pseudoaneurysm. Journal of Nepal Medical Association, 2015;53(198), 130-133. PMID: 26994035

13. Bernik TR, Friedman SG, Scher LA, Safa T. Pseudoaneurysm of the Subclavian-Vertebral Artery Junction. Vascular and Endovascular Surgery, 2002;36(6), 461-464. PMID: 12476236

14. Anastasiadou C, Giannakakis S, Galyfos G, Livieratos L, Kastrisios G, Papapetrou A, Maltezos C. Giant Dorsalis Pedis Pseudoaneurysm Following Cannulation for Arterial Line in a Patient with Systemic Lupus Erythematosus. Vasc Specialist Int. 2019 Jun;35(2):114-117. PMID: 31297363

15. Putnam JS, Uchida BT, Antonovic R, Rösch J. Superior vena cava syndrome associated with massive thrombosis: treatment with expandable wire stents. Radiology. 1988 Jun;167(3):727-8. PMID: 3363130

16. Rösch J, Uchida BT, Hall LD, Antonovic R, Petersen BD, Ivancev K, Barton RE, Keller FS. Gianturco-Rösch expandable Z-stents in the treatment of superior vena cava syndrome. Cardiovasc Intervent Radiol. 1992 SepOct;15(5):319-27. PMID: 1423393

17. Petersen BD, Uchida BT, Barton RE, Keller FS, Rösch J. Gianturco-Rösch Z stents in tracheobronchial stenoses. J Vasc Interv Radiol. 1995 Nov-Dec;6(6):925-31. PMID: 8850671

18. Miyazaki K, Nishibe $\mathrm{T}$, Manase $\mathrm{H}$, Ohkashiwa $\mathrm{H}$, Takahashi T, Watanabe S, et al. Gianturco stents for the venous system: A detailed pathological study. Surg Today 1998;28:396-400. PMID: 9590704

19. Bai H, Masuda J, Sawa Y, et al. Neointima formation after vascular stent implantation. Spatial and chronological 
distribution of smooth muscle cell proliferation and phenotypic modulation. Arterioscler Thromb. 1994;14(11):1846-1853. PMID: 7947611

20. Trerotola SO, Fair JH, Davidson D, Samphilipo MA, Magee CA. Comparison of Gianturco Z Stents and Wallstents in a Hemodialysis Access Graft Animal Model. J Vasc Interv Radiol 1995;6:387-96. PMID: 7647440

21. Puma F, Farabi R, Urbani M, Santoprete S, Daddi N, Di Meo A, et al. Long-term safety and tolerance of silicone and self-expandable airway stents: An experimental study. Ann Thorac Surg 2000;69:1030-4. PMID: 10800789

22. Ohta N, Waki T, Fukase S, Suzuki Y, Kurakami K, Aoyagi M, Kakehata S. Aortic aneurysm rupture as a rare complication of granulomatosis with polyangiitis: a case report. J Med Case Rep. 2013 Jul 26;7:202. PMID: 23889996
23. Niimi N, Miyashita T, Tanji K, Hirai T, Watanabe K, Ikeda K, Morimoto S, Sekigawa I. Aortic Aneurysm as a Complication of Granulomatosis with Polyangiitis Successfully Treated with Prednisolone and Cyclophosphamide: A Case Report and Review of the Literature. Case Rep Rheumatol. 2018 Jun 5;2018:9682801. PMID: 29971178

24. Shitrit D, Shitrit AB, Starobin D, Izbicki G, Belenky A, Kaufman N, Kramer MR. Large vessel aneurysms in Wegener's granulomatosis. J Vasc Surg. 2002 Oct;36(4):8568. PMID: 12368751

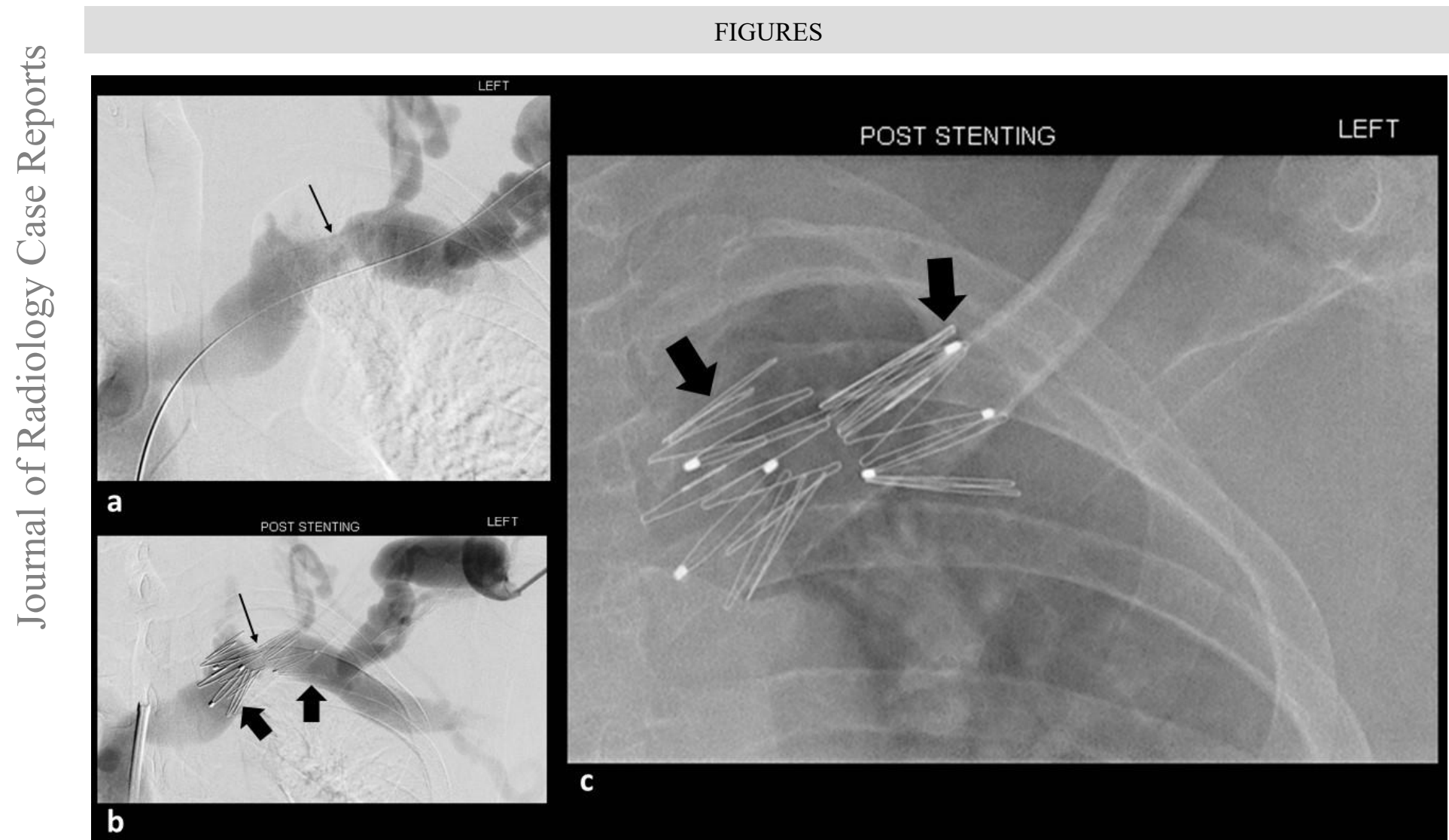

Figure 1: 49-year-old male with granulomatosis with polyangiitis presenting with exertional dyspnea and intermittent cough. He had a history of left arm hemodialysis access issues with multiple interventions. This procedure was performed 8 years prior to the current admission.

FINDINGS: Venogram showed moderate left subclavian vein stenosis (small arrows) with a dilated tortuous external jugular vein and cephalic arch. A $40 \times 50 \mathrm{~mm}$ Gianturo stent was deployed across the stenosis with final position as shown (large arrows). Treatment result was suboptimal.

TECHNIQUE: Toshiba MEC DFP-8000D, 50 ml IV Omnipaque 300. 


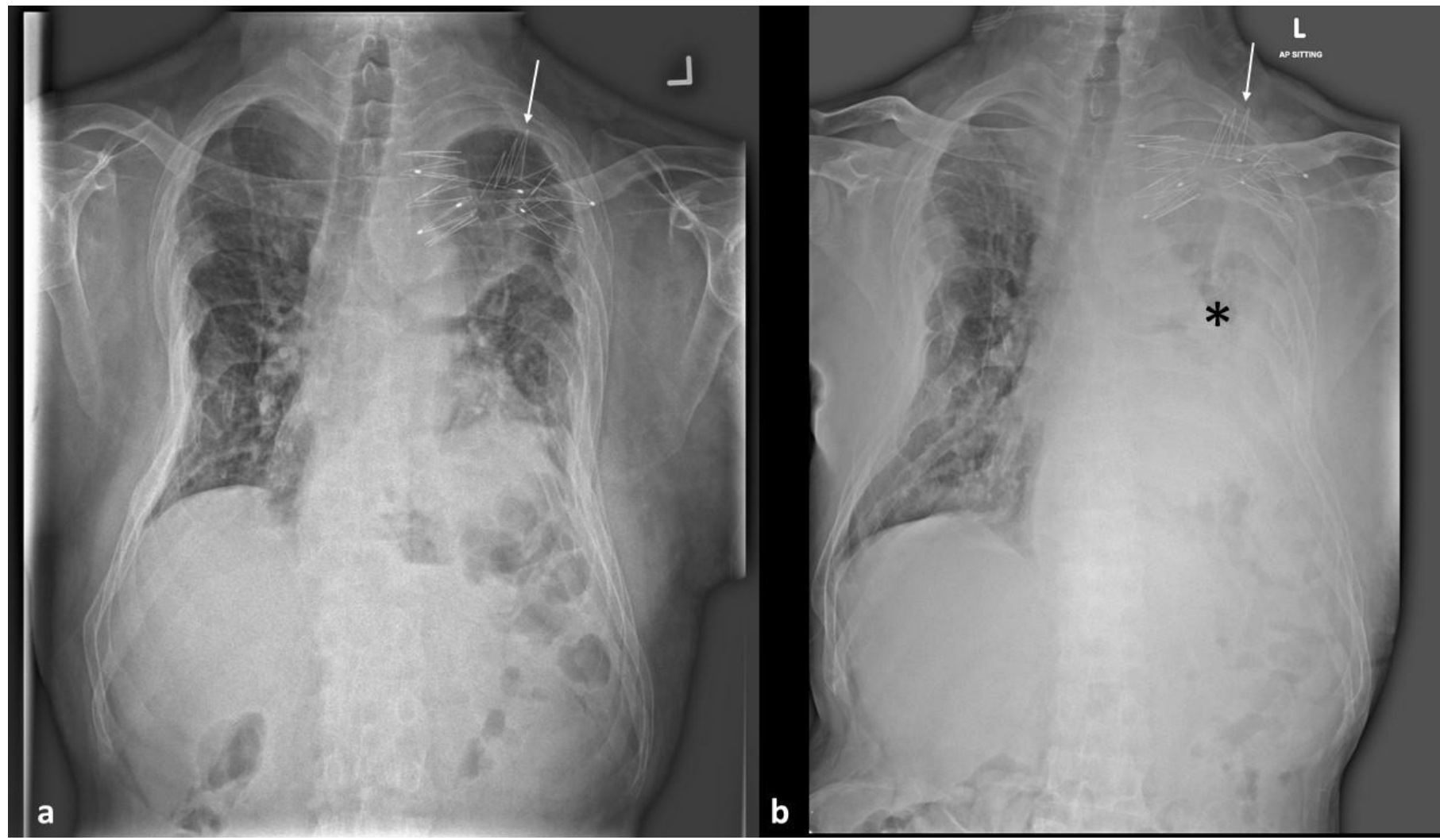

Figure 2: 49-year-old male with granulomatosis with polyangiitis presenting with exertional dyspnea and intermittent cough.

FINDINGS: Comparison chest radiographs done a week apart show progressive white-out of the left hemithorax (asterisk). Nodular opacities in the right lung are grossly unchanged from the CT 6 months ago given intermodality differences (Fig 4). The left subclavian vein Gianturco stent remains in situ (arrow); the lateral end of the stent now appears mangled and deformed compared to when it was deployed (Fig 1). Multiple old bilateral rib fractures.

TECHNIQUE: Anteroposterior (AP) sitting chest radiographs.

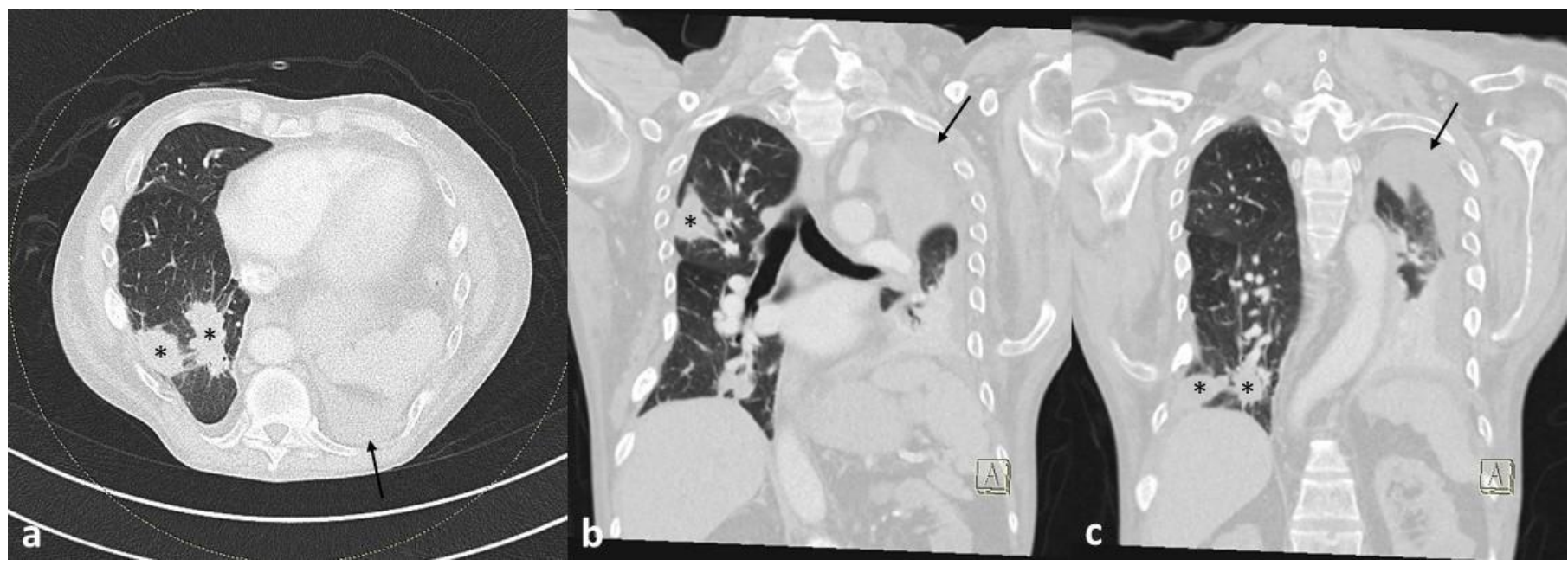

Figure 3: 49-year-old male with granulomatosis with polyangiitis presenting with exertional dyspnea and intermittent cough. CT performed for further evaluation of chest radiograph findings.

FINDINGS: Multiple recurring nodular lesions in both lungs (asterisks), some of which were cavitating 8 months ago (Fig 4). New left pleural effusion and left lung collapse (arrows). Multiple old bilateral rib fractures.

TECHNIQUE: Axial contrast enhanced CT thorax with coronal reformation, venous phase, Siemens Somatom Force, dual energy, 90/150 kilovolt (kV), 47/39 milliampere (mA), 3 mm slice thickness, $50 \mathrm{ml}$ IV Omnipaque 350. 

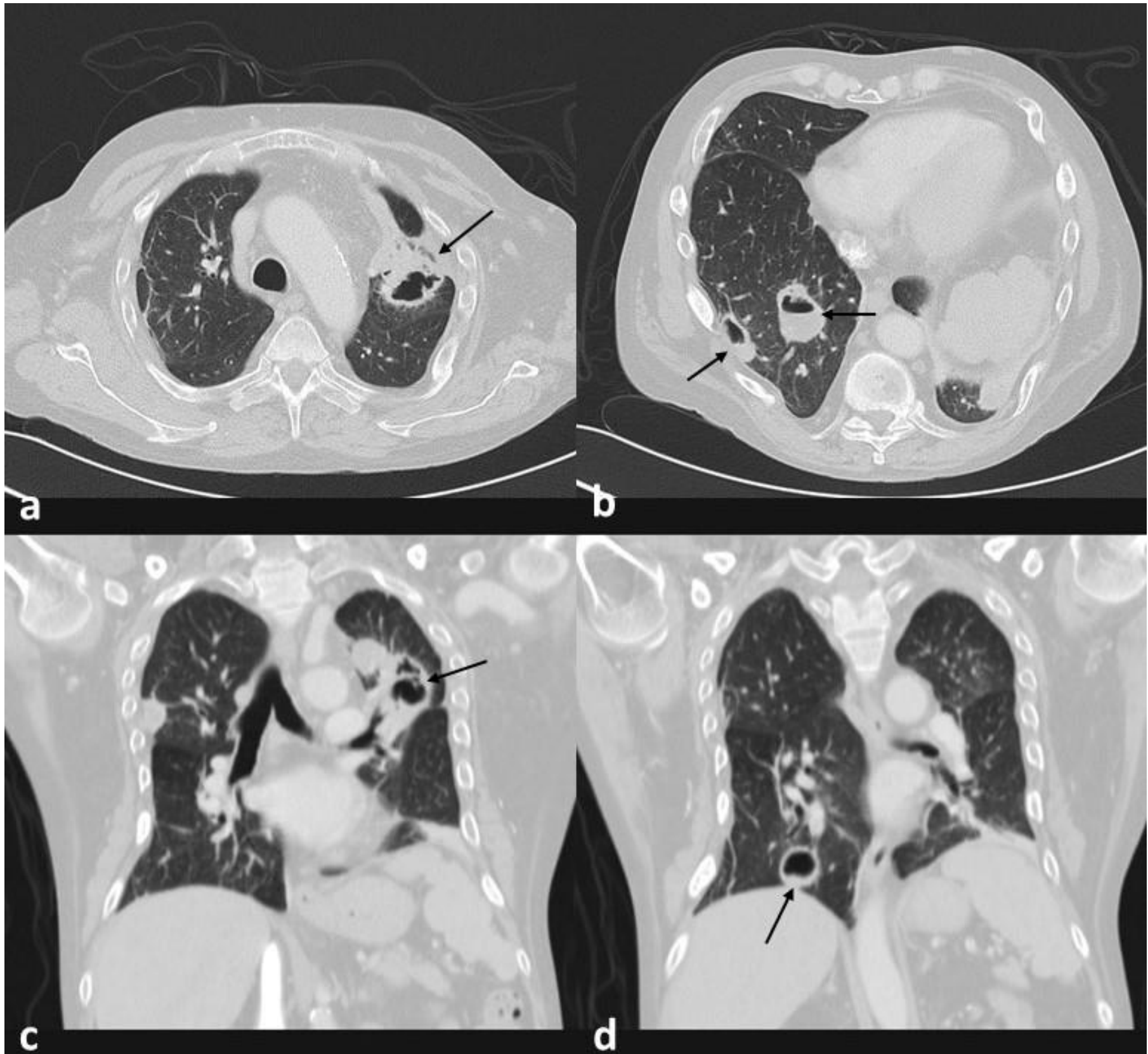

Figure 4: 49-year-old male with granulomatosis with polyangiitis presenting with exertional dyspnea and intermittent cough. This is a comparison CT 8 months prior to the current admission.

FINDINGS: Multiple cavitating nodular lesions in both lungs (arrows). Multiple old bilateral rib fractures.

TECHNIQUE: Axial contrast enhanced CT thorax with coronal reformation, venous phase, Siemens Sensation Cardiac, $120 \mathrm{kV}$, $118 \mathrm{~mA}, 3 \mathrm{~mm}$ slice thickness, $50 \mathrm{ml}$ IV Omnipaque 350. 

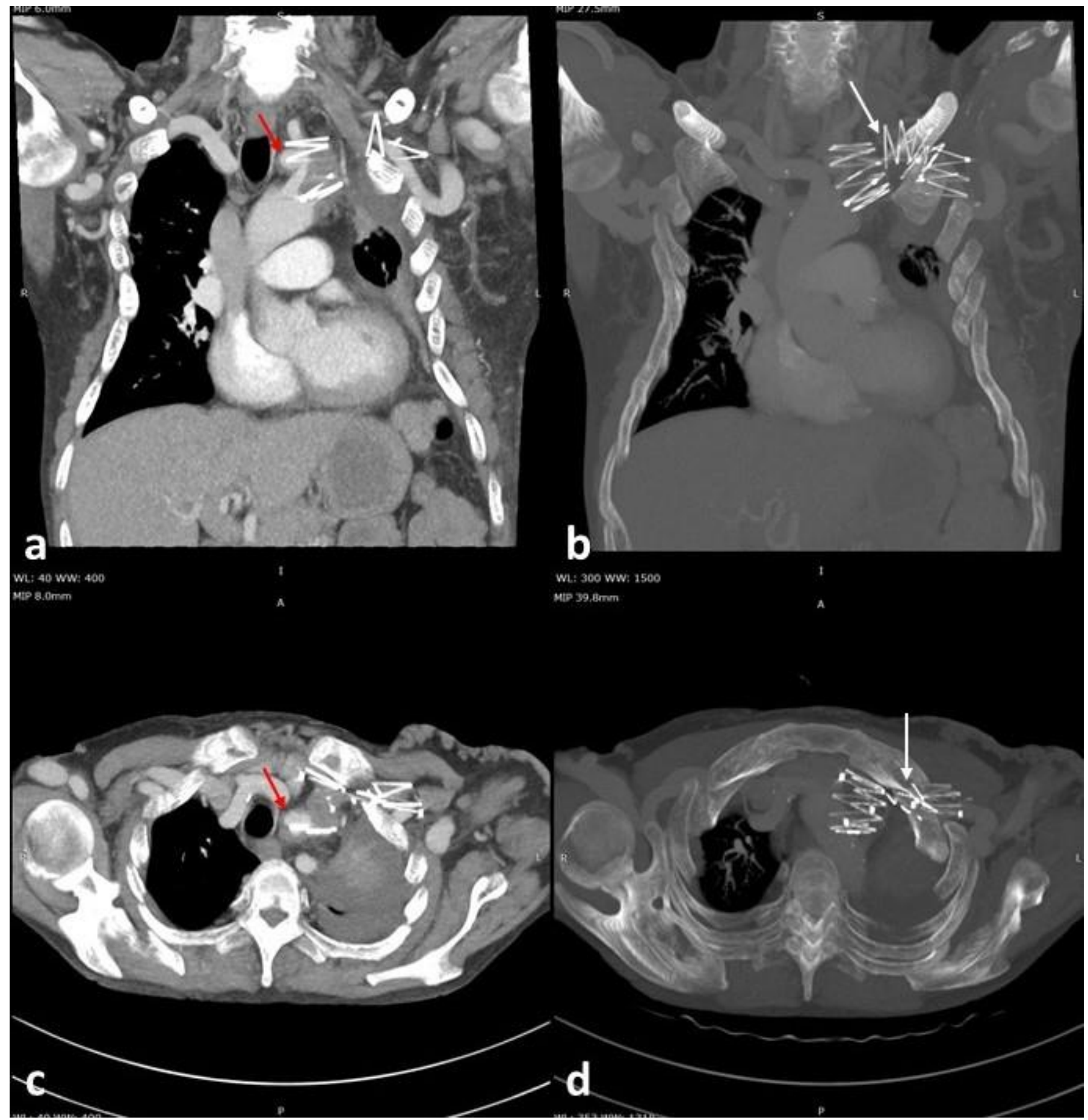

Figure 5: 49-year-old male with granulomatosis with polyangiitis presenting with exertional dyspnea and intermittent cough. CT performed for further evaluation of chest radiograph findings.

FINDINGS: A contrast filled saccular outpouching arising from the proximal left common carotid artery adjacent to the protruding struts of the left subclavian vein Gianturco stent is new from 8 months ago, in keeping with a pseudoaneurysm (red arrows). The lateral end of the stent now appears mangled and deformed (white arrows) compared to when it was deployed (Fig 1). New left pleural effusion and left lung collapse. Multiple old bilateral rib fractures.

TECHNIQUE: Maximum intensity projection (MIP), axial contrast enhanced CT thorax with coronal reformation, venous phase, Siemens Somatom Force, dual energy, 90/150 kV, 47/39 mA, 3 mm slice thickness, 50 ml IV Omnipaque 350. 


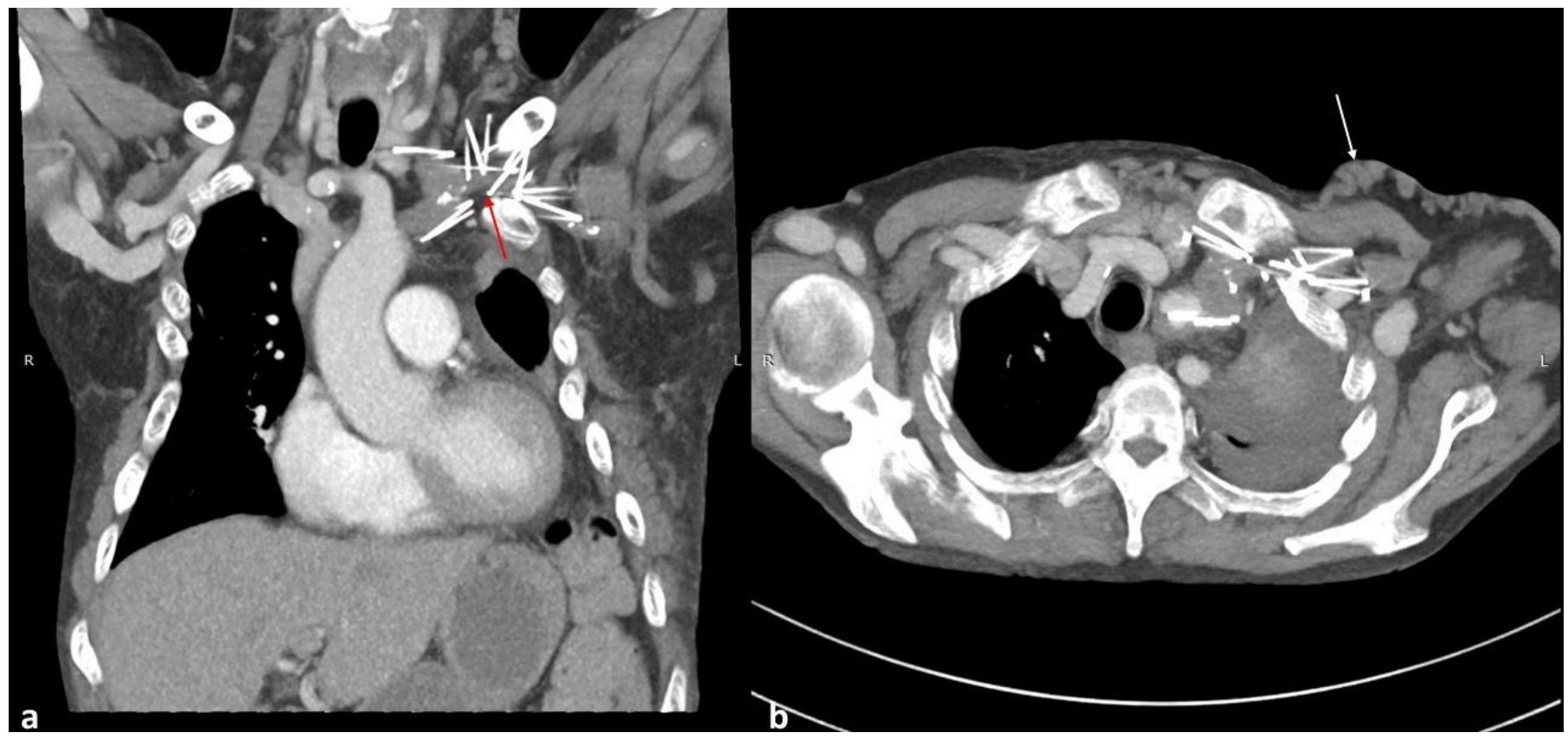

Figure 6: 49-year-old male with granulomatosis with polyangiitis presenting with exertional dyspnea and intermittent cough. CT performed for further evaluation of CXR findings.

FINDINGS: The lateral end of the left subclavian vein Gianturco stent now appears mangled and deformed compared to when it was deployed (Fig 1). The left subclavian vein appears occluded (red arrow) with prominent left upper chest wall collaterals seen (white arrow). New left pleural effusion and left lung collapse. Multiple old bilateral rib fractures.

TECHNIQUE: MIP, axial contrast enhanced CT thorax with coronal reformation, venous phase, Siemens Somatom Force, dual energy, $90 / 150 \mathrm{kV}, 47 / 39 \mathrm{~mA}, 3 \mathrm{~mm}$ slice thickness, $50 \mathrm{ml}$ IV Omnipaque 350
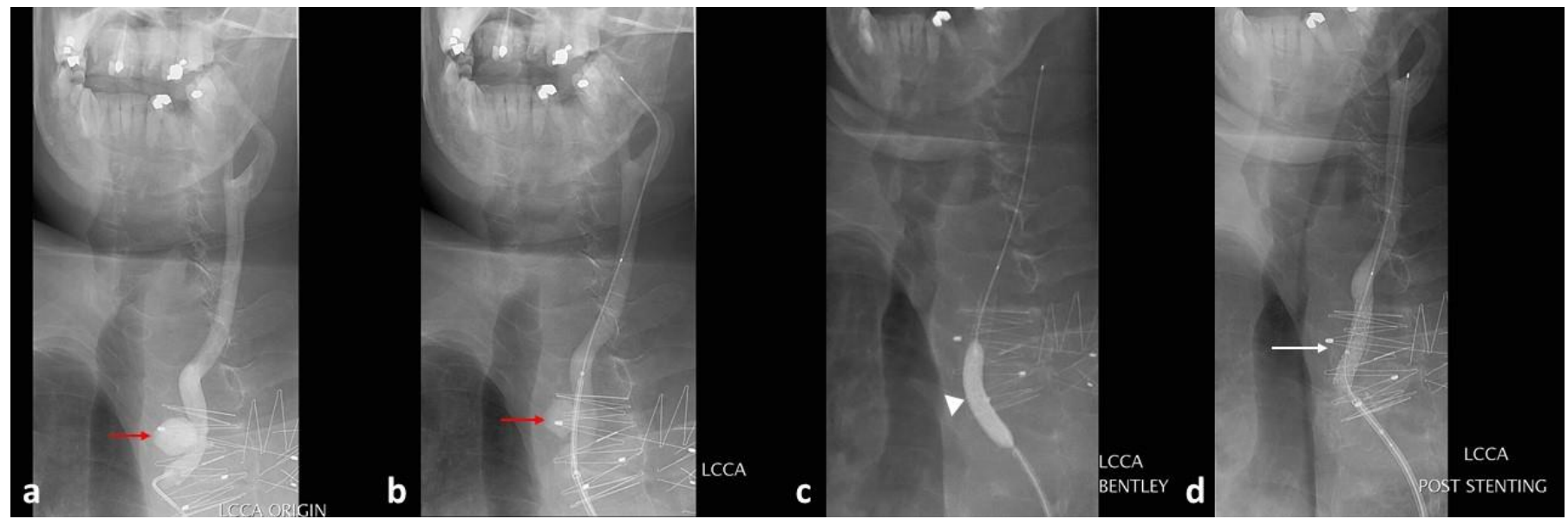

Figure 7: 49-year-old male with granulomatosis with polyangiitis with pulmonary involvement and superimposed infection. Incidental left common carotid artery pseudoaneurysm detected on CT for evaluation of lung findings, referred for endovascular management.

FINDINGS: Left common carotid angiogram shows a focal pseudoaneurysm sac at its proximal segment, pointing medially (red arrows). The left subclavian vein Gianturco stent struts are projected over the proximal left common carotid artery. A 7 x 37 mm BeGraft peripheral stent was deployed across the neck of the pseudoaneurysm. The proximal extent of the stented segment (at the ostium of the left common carotid artery) was further dilated to 'flare' the edge (white arrow head). Final angiogram confirms occlusion of the pseudoaneurysm (white arrow).

TECHNIQUE: Toshiba MEC DFP-8000D, $120 \mathrm{ml}$ intra-arterial (IA) Omnipaque 300. 


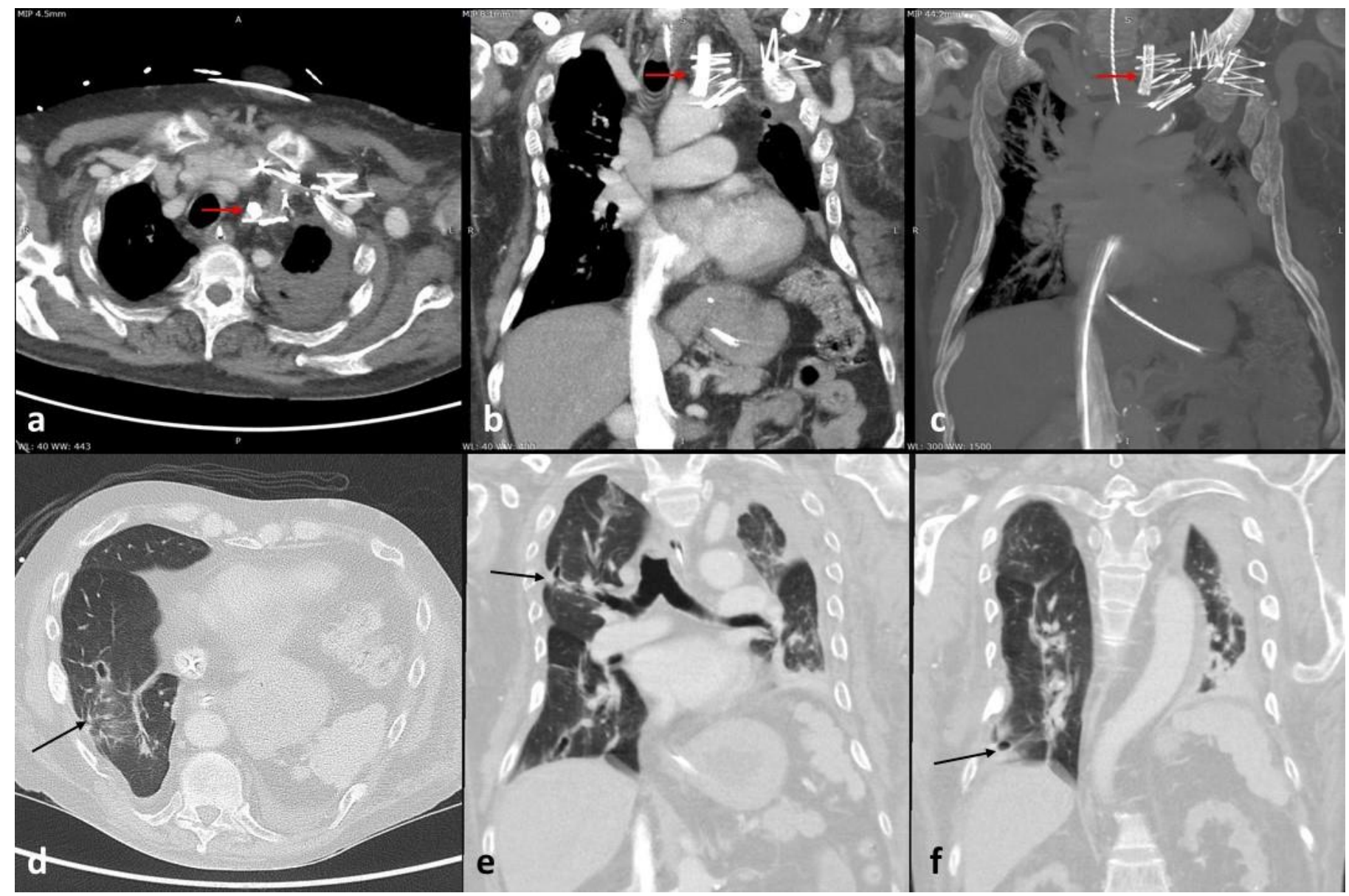

Figure 8: 49-year-old male with granulomatosis with polyangiitis with pulmonary involvement and superimposed infection, and left common carotid artery pseudoaneurysm. Follow up CT 4 months post endovascular treatment of the left common carotid artery pseudoaneurysm.

FINDINGS: There is continued occlusion of the left common carotid artery pseudoaneurysm post stenting (red arrows) and patency of the stent. Interval improvement of the lung nodules (black arrows) compared to before (Fig 3). The left pleural effusion is still present. Feeding tube in situ. Multiple old bilateral rib fractures.

TECHNIQUE: MIP (Fig 8a to 8c), axial contrast enhanced CT thorax with coronal reformation, venous phase, Philips iCT 256, $100 \mathrm{kV}, 141 \mathrm{~mA}, 3 \mathrm{~mm}$ slice thickness, $80 \mathrm{ml}$ IV Omnipaque 350.

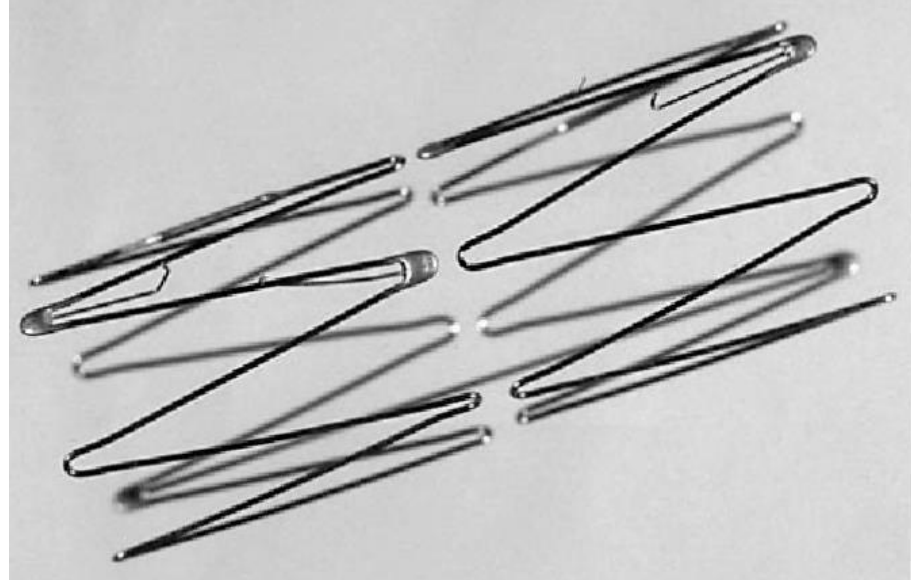

Figure 9 (left): 49-year-old male with granulomatosis with polyangiitis. He had a history of left subclavian vein stenosis treated with a Gianturco stent, pictured here. 


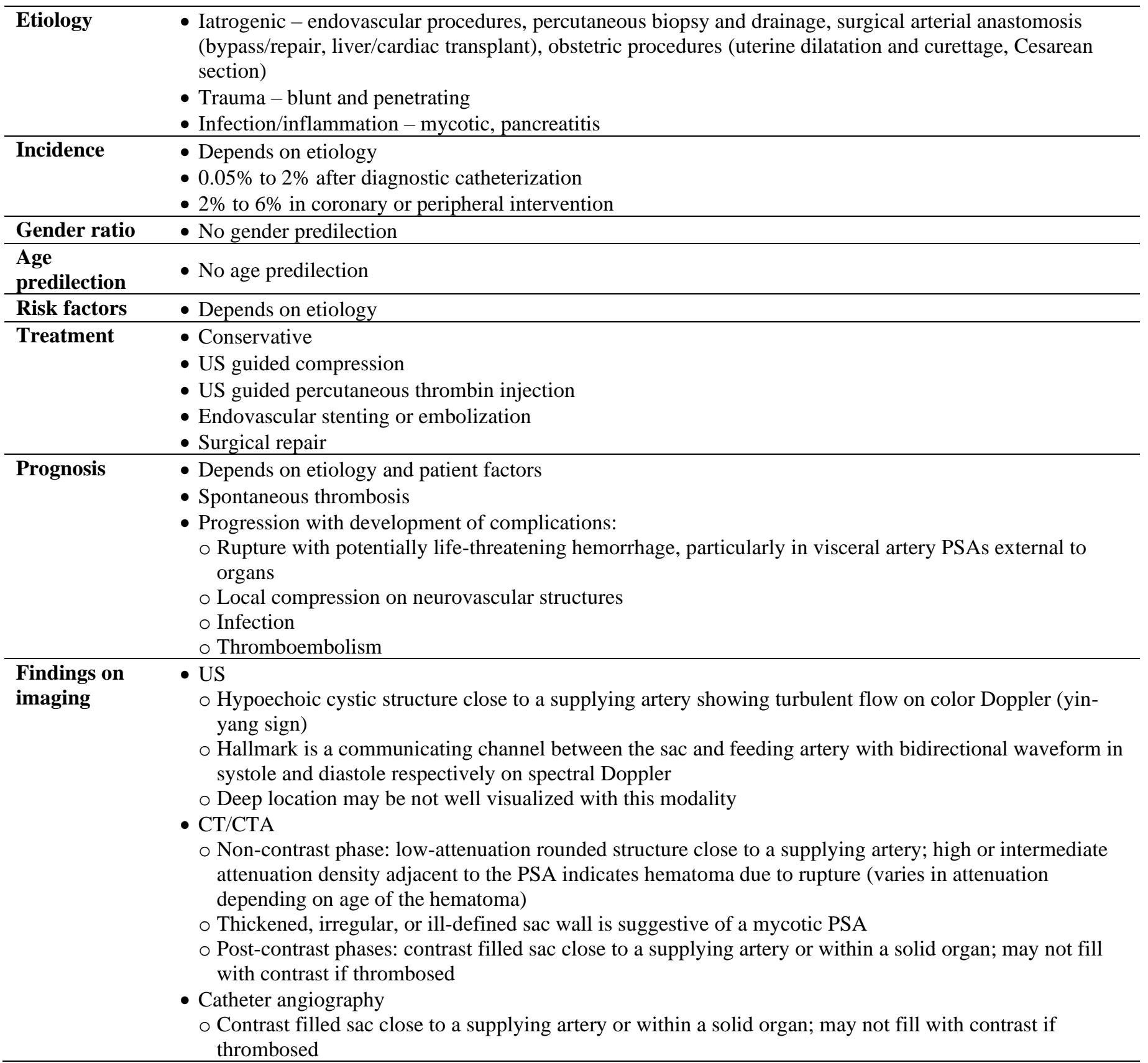

Table 1: Summary table of the salient clinical and imaging features of pseudoaneurysms 


\begin{tabular}{|c|c|c|c|c|}
\hline $\begin{array}{l}\text { Differential } \\
\text { diagnosis }\end{array}$ & Clinical & US & CT/CTA & Catheter angiography \\
\hline $\begin{array}{l}\text { Iatrogenic } \\
\text { PSA }\end{array}$ & $\begin{array}{l}\text { - Previous } \\
\text { endovascular } \\
\text { procedures } \\
\text { - Non-vascular } \\
\text { percutaneous } \\
\text { procedures (biopsy, } \\
\text { drainage) } \\
\text { - Surgical procedures } \\
\text { involving arterial } \\
\text { anastomosis } \\
\text { (arterial } \\
\text { bypass/repair, } \\
\text { transplantation) } \\
\text { - Obstetric procedures } \\
\text { (uterine dilatation } \\
\text { and curettage, } \\
\text { Cesarean section) }\end{array}$ & $\begin{array}{l}\text { 1. Hypoechoic cystic } \\
\text { structure close to a } \\
\text { supplying artery or } \\
\text { within a solid organ } \\
\text { showing turbulent } \\
\text { flow on color } \\
\text { Doppler (yin-yang } \\
\text { sign) } \\
\text { 2. Hallmark is a } \\
\text { communicating } \\
\text { channel between the } \\
\text { sac and feeding artery } \\
\text { with bidirectional } \\
\text { waveform in systole } \\
\text { and diastole } \\
\text { respectively on } \\
\text { spectral Doppler } \\
\text { 3. Deep location may be } \\
\text { not well visualized } \\
\text { with this modality }\end{array}$ & $\begin{array}{l}\text { 1. Non-contrast phase: } \\
\text { low-attenuation rounded } \\
\text { structure close to a } \\
\text { supplying artery } \\
\text { 2. Post-contrast phases: } \\
\text { contrast filled sac close } \\
\text { to a supplying artery or } \\
\text { within a solid organ; } \\
\text { may not fill with } \\
\text { contrast if thrombosed } \\
\text { 3. Presence of catheter, } \\
\text { graft, stent } \\
\text { 4. Evidence of previous } \\
\text { intervention/surgery - } \\
\text { coils, clips etc. }\end{array}$ & $\begin{array}{l}\text { 1. Contrast filled sac } \\
\text { close to a supplying } \\
\text { artery or within a solid } \\
\text { organ; may not fill } \\
\text { with contrast if } \\
\text { thrombosed } \\
\text { 2. Presence of catheter, } \\
\text { graft, stent } \\
\text { 3. Evidence of previous } \\
\text { intervention/surgery - } \\
\text { coils, clips etc. }\end{array}$ \\
\hline $\begin{array}{l}\text { Traumatic } \\
\text { PSA }\end{array}$ & - Recent trauma & $\begin{array}{l}\text { - Same as iatrogenic } \\
\text { PSA }\end{array}$ & $\begin{array}{l}\text { - Same as } 1 \text { and } 2 \text { for } \\
\text { iatrogenic PSA } \\
\text { - Co-existing solid organ } \\
\text { laceration/rupture } \\
\text { - Other trauma related } \\
\text { findings such as fractures } \\
\text { and foreign bodies }\end{array}$ & $\begin{array}{l}\text { - Same as } 1 \text { for iatrogenic } \\
\text { PSA } \\
\text { - Other trauma related } \\
\text { findings such as } \\
\text { fractures and foreign } \\
\text { bodies }\end{array}$ \\
\hline $\begin{array}{l}\text { Infectious / } \\
\text { inflammatory } \\
\text { PSA }\end{array}$ & $\begin{array}{l}\text { - Febrile, septic, } \\
\text { raised inflammatory } \\
\text { markers } \\
\text { - Multisystem } \\
\text { involvement in } \\
\text { systemic vasculitis } \\
\text { - History of alcohol } \\
\text { excess or } \\
\text { cholelithiasis and } \\
\text { elevated serum } \\
\text { amylase and lipase } \\
\text { in pancreatitis } \\
\end{array}$ & $\begin{array}{l}\text { - Same as iatrogenic } \\
\text { PSA }\end{array}$ & $\begin{array}{l}\text { - Same as } 1 \text { and } 2 \text { for } \\
\text { iatrogenic PSA } \\
\text { - Thickened, irregular, or } \\
\text { ill-defined sac wall } \\
\text { - Surrounding } \\
\text { inflammatory changes }\end{array}$ & $\begin{array}{l}\text { - Same as } 1 \text { for iatrogenic } \\
\text { PSA }\end{array}$ \\
\hline $\begin{array}{l}\text { True } \\
\text { aneurysm }\end{array}$ & $\begin{array}{l}\text { - Cardiovascular risk } \\
\text { factors } \\
\text { - Connective tissue } \\
\text { diseases }\end{array}$ & $\begin{array}{l}\text { - Same as iatrogenic } \\
\text { PSA }\end{array}$ & $\begin{array}{l}\text { - Non-contrast phase: } \\
\text { fusiform dilatation or } \\
\text { saccular outpouching in } \\
\text { continuity with the artery } \\
\text { - Post-contrast phases: } \\
\text { contrast filled fusiform } \\
\text { dilatation or saccular } \\
\text { outpouching in } \\
\text { continuity with the artery } \\
\text { if not thrombosed }\end{array}$ & $\begin{array}{l}\text { - Contrast filled fusiform } \\
\text { dilatation or saccular } \\
\text { outpouching in } \\
\text { continuity with the } \\
\text { artery if not thrombosed }\end{array}$ \\
\hline
\end{tabular}

Table 2: Differential diagnosis table for a pseudoaneurysm 


\section{ABBREVIATIONS}

$\mathrm{AP}=$ Anteroposterior

$\mathrm{CXR}=$ Chest X-Ray

$\mathrm{CCA}=$ Common Carotid Artery

CT = Computed Tomography

CTA = Computed Tomography Angiography

GCA $=$ Giant cell arteritis

GPA $=$ Granulomatosis with polyangiitis

IA = Intra-arterial

$\mathrm{IV}=$ Intravenous

$\mathrm{kV}=$ Kilovolt

MR = Magnetic Resonance

MRA = Magnetic Resonance Angiography

MIP = Maximum intensity projection

$\mathrm{mA}=$ Milliampere

PAN $=$ Polyarteritis nodosa

PSA $=$ Pseudoaneurysm

SLE = Systemic lupus erythematosus

SVCS = superior vena cava syndrome

US = Ultrasonography

\section{KEYWORDS}

Subclavian vein stenosis; Gianturco stent; perforation; pseudoaneurysm; granulomatosis with polyangiitis

\section{Online access}

This publication is online available at:

www.radiologycases.com/index.php/radiologycases/article/view/3903

\section{Peer discussion}

Discuss this manuscript in our protected discussion forum at: www.radiolopolis.com/forums/JRCR

\section{Interactivity}

This publication is available as an interactive article with scroll, window/level, magnify and more features.

Available online at www.RadiologyCases.com

\section{Published by EduRad}

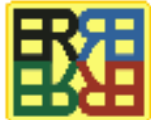

www.EduRad.org 